\title{
Design of Slotted and Slotless AFPM Synchronous Generators and their Performance Comparison Analysis by using FEA Method
}

\author{
Saint Saint Soe, Yan Aung Oo \\ Department of Electrical Power Engineering, Mandalay Technological University \\ Mandalay, Myanmar
}

\begin{tabular}{l} 
Article Info \\
\hline Article history: \\
Received Mar 11, 2015 \\
Revised May 10, 2015 \\
Accepted May 24, 2015 \\
\hline Keyword: \\
Axial-flux permanent magnet \\
Double-rotor \\
Finite-element method \\
Slotless stator \\
Slotted stator \\
Synchronous generator
\end{tabular}

\begin{abstract}
Axial-flux permanent magnet machines are popular and widely used for many applications due to their attractive features such as light weight, low noise, high torque, robust and higher efficiency due to lack of field excitation. The main essence of this paper is to perform slotted and slotless axial-flux permanent magnet synchronous generator design based on theoretical sizing equations and then finite element analysis is reinforcement in order to get a more reliable and accuracy machine design. A comparative study of machine design and performances over the same rating but different configurations i.e., slotted and slotless are also discussed. And then, finiteelement method (FEM) software was made for the slotted stator and slotless stator (AFPMSG) in order to compare their magnetic flux density and efficiency. The AFPMSG topology considered in this paper is a three-phase double-rotor single-stator topology with 16 pole-pairs, $2 \mathrm{~kW}$ rated power and $188 \mathrm{rpm}$ rated speed.
\end{abstract}

Copyright (C) 2015 Institute of Advanced Engineering and Science. All rights reserved.

\section{Corresponding Author:}

Saint Saint Soe,

Department of Electrical Power Engineering, Mandalay Technological University

Mandalay, Myanmar.

Email: seintssoe@gmail.com

\section{INTRODUCTION}

Having the high torque at low speeds, the axial- flux permanent-magnet synchronous machine AFPMSM is very suitable for wheel motors, direct drive wind energy applications and so on. As the pole number is chosen sufficiently high, a high torque density combined with a good performance at low speeds is obtained. The efficient exploitation of the machine, even at very low speeds, permits direct coupling of the machine to the low speed application without using a gearbox. Compared with a conventional, gearboxcoupled wind turbine generator, a direct coupled generator system eliminates mechanical reduction gear, reduces size of the overall system, lower installation and maintenance costs. The use of direct drive wind energy generator will result less maintenance and increased in reliability significantly. As the magnetic field is generated by the permanent magnets, no field excitation current is necessary and the corresponding copper losses are absent. As a consequence, AFPM machines have a good efficiency.

AFPMS machines exist in different topologies and geometries such as single-sided or double-sided, with or without armature slots, with or without armature core, with internal or external PM rotors, each having their advantages and disadvantages [1]. The AFPMSM discussed in this paper is a single-stator double-rotor type with slotted stator and slotless stator.

In the case of double-sided configurations, either external dual-rotor with slotted stator or external dual rotor with slotless stator arrangement can be adopted. The two constructive types of wind-turbine generator considered in this work are permanent-magnet synchronous generators, but one has a slotted stator axial-flux (AFPMSG) topology, the other one is of slotless (air-cored) stator axial-flux (AFPMSG) type. In 
the following sections, each of the two PMSG topologies is investigated using finite-element field analysis to comparatively show their magnetic flux density.

\section{AXIAL FLUX PM SYNCHRONOUS GENERATOR}

Axial-flux PMSGs have a number of distinct advantages, i.e. they can be designed to have (i) higher power- to- weight ratio, resulting in less core material, (ii) planar and easily adjustable air-gaps, (iii) reduced noise and vibration levels. Moreover, the direction of the air gap flux path can be varied, so that additional topologies can be derived. This paper presents a comparative study between the axial-flux slotted stator and slotless (air-cored) stator permanent-magnet synchronous generators for a $2 \mathrm{~kW}$ wind turbine application. The magnets are of high-energy $\mathrm{NdFeB}$ type, and are glued on both sides of the two solid-iron disc-rotors.

\subsection{Double-Sided AFPMSG Slotless (Air-Cored) Stator}

In a coreless AFPM machine the stator is located between the two opposing rotor discs. Figure 1 shows the machine has a single stator sandwiched between two PM rotor discs [2]. The air-cored (ironless) nature of the stator eliminated the lamination stamping during the manufacturing process of the stator winding.

However, there is no iron in the stator of this machine, instead the windings are placed in the air gap and epoxy encapsulated. The absence of the iron core for the coils of the stator winding creates a low flux density in the magnetic circuit of the coil, resulting in a low value of inductance for the coil in the coreless stator [3]. The stator winding of the AFPM machine in this paper is using the single-layer trapezoidal coil shape. The advantage of the trapezoidal coil shape is that it allows for the maximum coil flux linkage.

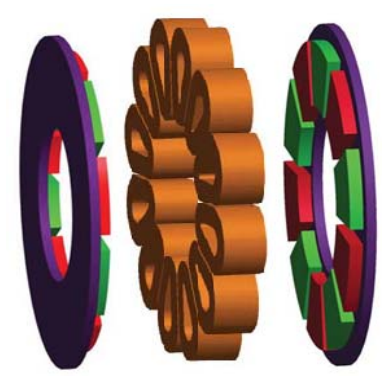

Figure 1. Double-sided AFPM machine with internal air cored stator

Due to the absence of stator iron, the flux travels from the north-pole of one rotor disc through the air gap to the south-pole of the other disc and returns by travelling circumferentially around the rotor back iron. Therefore, in the machine with air-cored stator, the north-pole of one rotor directly faces the south-pole of the other rotor. The machine with air cored stator has the same advantages as the TORUS machine such as elimination of cogging and easy integration to turbine due to outer rotor configuration. In addition the absence of iron in the stator eliminates stator iron losses and increases generator efficiency.

\subsection{Double-Sided AFPMSG Slotted Stator}

The double-sided structure with external rotor simplifies the manufacture process due to easier fixation of the stator rings to the frame; it also favours the cooling process because the main heat source is located near the surface. Slotted stators increase remarkably the amplitude of the air gap flux density due to shorter air gap [4]. Due to the slotted nature, the air gap is smaller but the flux distribution may contain harmonic, transmitted to the load as a torque ripple. Associated with the slotted core are tooth saturation problems and additional iron loss in the teeth. The efficiencies of this stator design are not the highest achievable. 


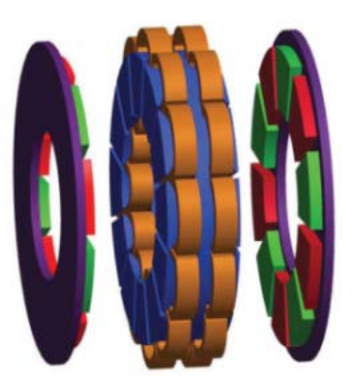

Figure 2. Double-rotor single-slotted stator structure (AFPMSG)

\subsection{PM Mounting Type for Slotted Stator}

The magnetic flux in these structures are showed in two derivations, the Torus-NN and the TorusNS, as shown in the Figure 3(a) and Figure 3(b). The depicted figures show a slotted stator, however the flux directions are also valid for stators without slots.

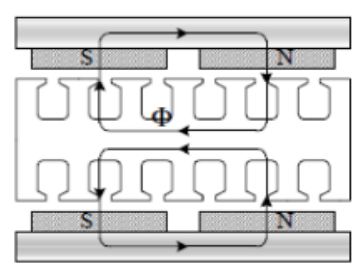

(a) NN type

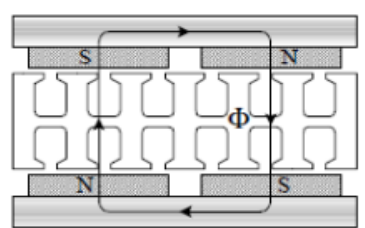

(b) NS type

Figure 3. Direction of the flux for axial flux machines with slotted stator type NN and NS

\subsection{Comparison of NN Type and NS Type}

There are two types of rotor construction for an AFPMSG. They are NN type rotor and NS type rotor. North-north (NN) structure has main flux to flow circumferentially along the stator core, so a thick stator yoke is required, hence increase iron losses exists. NN structure thus has less copper losses and smaller external diameter, but more iron losses and longer axial. North-south (NS) structure has main flux flowing axially through stator, so in principle, thick stator yoke is unnecessary. Iron losses are thus reduced, but lap windings lengthen end windings, which again increase copper losses.

By comparison of the NS and NN structure, the shorter stator yoke in the NS topology results in a increasing power density and lower stator core loss compared to the NN topology[5]. The axial thickness of the stator can be less than NN type machine. The NS feature results in less weight, less iron loss and higher efficiency than NN type machine. Here, NS construction has been selected because as stator core loss is less than NN type.

\section{COMPONENT OF THE AFPMSG}

This paper is designed for $2 \mathrm{~kW}$ axial-flux permanent magnet synchronous generator with coreless stator and slotted stator. The machine configuration consists of the following components: two rotor discs and one stator dick. They are external double-rotor and internal stator. The assigned value parameters of the AFPMSG for slotted stator and slotless stator are shown in Table 1.

Table 1. Specifications of AFPMSG

\begin{tabular}{ccc}
\hline Parameters & Units & Desired Value \\
\hline Number of phases & - & 3 \\
Number of pole pairs & - & 16 \\
Frequency & $\mathrm{Hz}$ & 50 \\
Rated voltage & $\mathrm{V}$ & 48 \\
Output power & $\mathrm{kW}$ & 2 \\
Specific electromagnetic loading & $\mathrm{A} / \mathrm{m}$ & 12000 \\
Connection of stator winding & - & star \\
\hline
\end{tabular}




\subsection{Design Equation for AFPMSG with Slotless Stator}

The axial-flux permanent magnet machine configuration consists of external double-rotor and internal air cored stator. Design calculation of $2 \mathrm{~kW}$ AFPMSG with air cored stator by using sizing equations is described in this section.

The effective air gap for the machine can be calculated by the following equation,

$$
1_{\text {geff }}=21_{g}+\frac{21_{m}}{\mu_{\text {rm }}}+h_{\text {sy }}
$$

The air gap flux density due to magnet for the slotless stator is the following equation,

$$
\mathrm{B}_{\mathrm{g}}=\frac{2 \mathrm{~B}_{\mathrm{rm}} 1_{\mathrm{m}}}{\mu_{\mathrm{rm}} 1_{\text {geff }}}
$$

The peak value of air-gap flux density,

$$
\mathrm{B}_{\mathrm{p}}=\frac{2 \sqrt{3} \times \mathrm{B}_{\mathrm{g}}}{\pi}
$$

The stator outer diameter for AFPMSG can be calculated by the following equation,

$$
\mathrm{D}_{\text {out }}=\sqrt[3]{\frac{\varepsilon \mathrm{P}_{\text {out }}}{\pi^{2} \lambda \mathrm{k}_{\mathrm{w}} \mathrm{n}_{\mathrm{s}} \mathrm{B}_{\mathrm{g}} \mathrm{A}_{\mathrm{m}} \eta \cos \phi}}
$$

The stator inner diameter for the AFPMSG,

$$
\mathrm{D}_{\text {in }}=\mathrm{D}_{\text {out }} \times \mathrm{K}_{\mathrm{D}}
$$

$\mathrm{K}_{\mathrm{D}} \quad$ = ratio of inner and outer diameter of machine

The RMS-value of the sinusoidal phase voltage of the non-overlapping winding can be calculated by the following equation,

$$
E_{\text {gen }}=\frac{q 2 \sqrt{2}}{a p} \omega_{e} B_{p} N_{t} r_{e} l_{a} k_{p} k_{d}
$$

The Stator copper losses,

$$
\mathrm{P}_{\mathrm{cu}}=3 \mathrm{I}_{\mathrm{ac}}^{2} \mathrm{R}_{\mathrm{i}}
$$

The Stator eddy current losses,

$$
\mathrm{P}_{\text {eddy }}=\frac{\pi \mathrm{l}_{\mathrm{a}} \mathrm{d}^{4} \mathrm{~B}_{\mathrm{p}}^{2} \omega_{\mathrm{e}}^{2} \mathrm{QN}_{\mathrm{t}} \mathrm{N}_{\mathrm{p}}}{32 \rho_{\mathrm{t}}}
$$

Output power of the generator can be calculated by,

$$
\mathrm{P}_{\mathrm{out}}=3 \mathrm{E}_{\mathrm{gen}} \mathrm{I}_{\mathrm{ac}} \cos \phi
$$

Input power of the generator is given by the following equation,

$$
\mathrm{P}_{\text {in }}=\mathrm{P}_{\text {out }}+\mathrm{P}_{\text {cu }}+\mathrm{P}_{\text {eddy }}
$$


Efficiency of the generator can be calculated by,

$$
\eta=\frac{P_{\text {out }}}{P_{\text {in }}} \times 100 \%
$$

The mechanical design parameters of the double-sided axial-flux permanent magnet synchronous generator for air-cored stator are shown in Table 2.

Table 2. Mechanical Design Parameters for Slotless Stator of AFPMSG

\begin{tabular}{ccc}
\hline Parameters & Units & Value \\
\hline Outer diameter of stator, & $\mathrm{cm}$ & 52.8 \\
Inner diameter of stator & $\mathrm{cm}$ & 30.5 \\
Outer radius of stator & $\mathrm{cm}$ & 26.4 \\
Inner radius of stator & $\mathrm{cm}$ & 15.3 \\
The number of turn per coil & turns & 37 \\
The total number of stator coil & - & 24 \\
Air gap distance & $\mathrm{mm}$ & 2 \\
Air gap flux density & $\mathrm{T}$ & 0.657 \\
The peak value of air gap flux density & $\mathrm{T}$ & 0.724 \\
\hline
\end{tabular}

\subsection{Design Equation for AFPMSG with Slotted Stator}

In a slotted AFPM machine, the stator outer diameter is assumed to be the same size as the slotless stator outer diameter and is also applied the same PM rotor discs. equation,

The air gap flux density due to magnet for the slotted stator can be calculated by the following

$$
\mathrm{B}_{\mathrm{g}}=\frac{21_{\mathrm{m}}}{\mu_{\mathrm{rm}} 1_{\text {geff }}} \times \mathrm{B}_{\mathrm{rm}} \times \frac{4}{\pi} \times \sin \left(\frac{\pi \mathrm{b}_{\mathrm{p}}}{\tau_{\mathrm{p}}}\right)
$$

The number of slot per pole per phase can be calculated by the following equation,

$$
\mathrm{q}_{1}=\frac{\mathrm{Z}_{1}}{2 \mathrm{pm}}
$$

The average pole pitch can be calculated by,

$$
\tau_{\mathrm{p}}=\frac{\pi \mathrm{D}_{\mathrm{avg}}}{2 \mathrm{p}}
$$
equation,

The RMS value of the induced phase voltage of the winding can be calculated by the following

$$
\mathrm{E}_{\mathrm{ph}}=\frac{4 \times \mathrm{f} \times \mathrm{k}_{\mathrm{w}} \times \mathrm{N}_{\mathrm{ph}} \times \mathrm{B}_{\mathrm{g}} \times \tau_{\mathrm{p}} \times 1_{\mathrm{s}}}{\sqrt{2}}
$$

Based on the calculated phase current and phase resistance, the copper losses in a stator winding are calculated as,

$$
\mathrm{P}_{\mathrm{Cu}}=\mathrm{mR} \mathrm{R}_{\mathrm{ph}}\left(\mathrm{I}_{\mathrm{ph}}\right)^{2}
$$

In the analytical approach the axial-flux PM machine is subdivided into yoke and teeth parts [6]. Therefore, the iron losses can be calculated as, 
$\mathrm{P}_{\mathrm{Fe}}=\left[\mathrm{k}_{\mathrm{Fe}, \mathrm{y}} \mathrm{P}_{1.0} \mathrm{G}_{\mathrm{y}} \mathrm{B}_{\mathrm{y}}{ }^{2}\left(\frac{\mathrm{f}}{50}\right)^{1.5}+\mathrm{k}_{\mathrm{Fe}, \mathrm{t}} \mathrm{P}_{1.0} \mathrm{G}_{\mathrm{t}} \mathrm{B}_{\mathrm{t}}{ }^{2}\left(\frac{\mathrm{f}}{50}\right)^{1.5}\right]$

The stray load losses are often considered to be a fraction of the output power,

$\mathrm{P}_{\text {str }}=\mathrm{k}_{\text {str }} \mathrm{P}_{\text {out }}$

$\mathrm{k}_{\mathrm{str}} \quad=$ the coefficient for stray load losses

The stray loss coefficient may to vary between 0.03 and 0.05 for machines rated up to $10 \mathrm{~kW}$ [7]. The output power of the machine can be calculated by the following equation,

$\mathrm{P}_{\text {out }}=\mathrm{mE}_{\mathrm{ph}} \mathrm{I}_{\mathrm{ph}} \cos \varphi$

The input power of axial-flux permanent magnet synchronous generator for slotted stator can be calculated by the following equation,

$$
\mathrm{P}_{\text {in }}=\mathrm{P}_{\text {out }}+\mathrm{P}_{\mathrm{Cu}}+\mathrm{P}_{\mathrm{Fe}}+\mathrm{P}_{\text {str }}
$$

The machine efficiency is obtained by using the input power and output power as,

$$
\eta=\frac{P_{\text {out }}}{P_{\text {in }}}
$$

The mechanical design parameters of the AFPMSG for slotted stator are shown in Table 3.

Table 3. Mechanical Design Parameters for Slotted Stator

\begin{tabular}{ccc}
\hline Parameters & Units & Value \\
\hline The number of slot per pole per phase & - & 1 \\
The number of total slot & - & 96 \\
The number of coil turns per phase & turns & 96 \\
The number of coil per phase & - & 18 \\
The number of turns per coil & turns & 9 \\
The axial length of the stator & $\mathrm{cm}$ & 3 \\
The yoke of the stator & $\mathrm{cm}$ & 1.7 \\
The depth of slot & $\mathrm{cm}$ & 1.05 \\
The width of tooth & $\mathrm{cm}$ & 1.82 \\
The average slot pitch & $\mathrm{cm}$ & 2.72 \\
The width of slot & $\mathrm{cm}$ & 0.9 \\
The air gap flux density & $\mathrm{T}$ & 1.24 \\
The peak value of air gap flux density & $\mathrm{T}$ & 1.37 \\
The average pole pitch & $\mathrm{cm}$ & 8.2 \\
\hline
\end{tabular}

\subsection{Comparison of Design Results for AFPMSG with Slotless Stator and Slotted Stator}

The output results of the axial-flux permanent magnet synchronous generator for slotted stator and slotless stator are shown in Table 4. 
Table 4. Electrical Design Results for AFPMSG

\begin{tabular}{ccc}
\hline Parameters & Slotless Value & Slotted Value \\
\hline The RMS value of the induced phase voltage & $48.44 \mathrm{~V}$ & $56 \mathrm{~V}$ \\
The phase current & $16.13 \mathrm{~A}$ & $14 \mathrm{~A}$ \\
The per phase stator resistance & $0.11 \Omega$ & $0.109 \Omega$ \\
The stator leakage inductance & $1.32 \mathrm{mH}$ & $0.49 \mathrm{mH}$ \\
The eddy current losses & $73.74 \mathrm{~W}$ & - \\
The copper losses & $85.85 \mathrm{~W}$ & $64.09 \mathrm{~W}$ \\
The iron losses & - & $63.7 \mathrm{~W}$ \\
The stray load losses & - & $80 \mathrm{~W}$ \\
The input power & $2.16 \mathrm{~kW}$ & $2.21 \mathrm{~kW}$ \\
The output power & $2 \mathrm{~kW}$ & $2 \mathrm{~kW}$ \\
The machine efficiency & $93 \%$ & $90 \%$ \\
\hline
\end{tabular}

According to the comparison results, the copper loss in slotless stator is higher than that of the slotted design. Moreover, the air cored stator has no iron loss but it also has eddy current loss in the statorwinding because the magnetic flux is directly exposed to the stator winding.

\section{PERFORMANCE ANALYSIS FOR AFPMSG}

Finite-element analysis allows modeling of complicated geometries, non linearity of the steel, in 2D and $3 \mathrm{D}$, and gives accurate results without standing on many restricting assumptions [8]. To analyze a problem, it should have an appropriate geometry, material properties, and excitation of a device or system of devices.

\subsection{Performance Analysis of Slotted Stator}

Evaluation of machine performance with the 2D FEA modelling axial-flux machines is possible in a similar way as it is with the analytical computation, i.e., by using the average radius of the machine as a design plane. In this study, the performance of 2kW AFPMSG with slotted stator is calculated with 2D finite element analysis. To run the FEA software, the first step is to draw the machine geometry with the calculated design parameters on the working plane. And then, material selection for each and every portion for the slotted stator design. The next step, mesh presentation is running condition which can be adjusted the mesh size defined in the properties of each material.

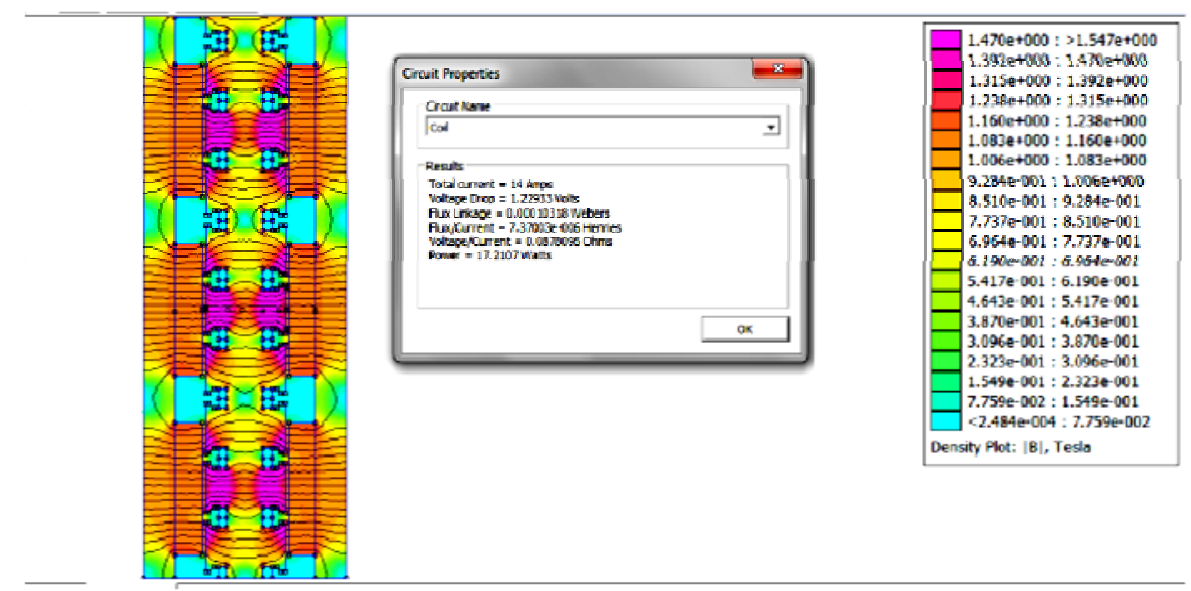

Figure 4. The magnetic flux density values for AFPMSG

Figure 4 shows the magnetic flux density values for AFPMSG by using FEM software. After running, these model display FEM result output, flux density which can be plotted as a colour density plot. 


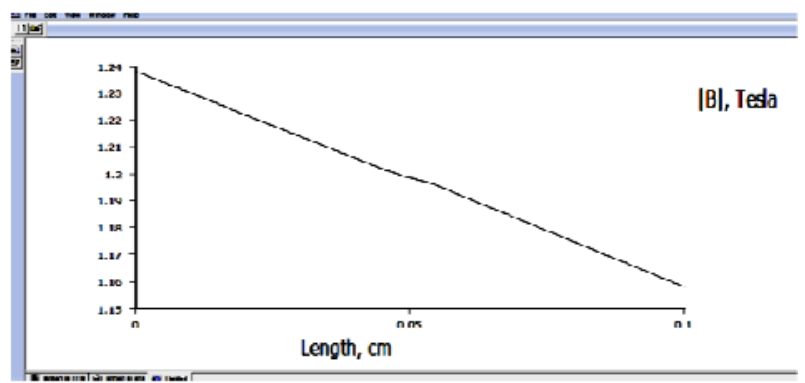

Figure 5. The peak value of air gap flux density plot for AFPMSG

Figure 5 is running result that is the peak value of air gap flux density plot for AFPMSG by using the finite-element analysis. In this figure, the peak value of air gap flux density is $1.238 \mathrm{~T}$.

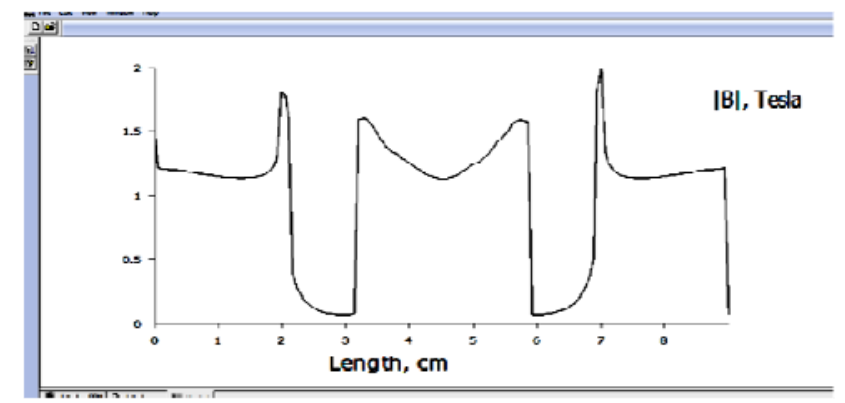

Figure 6. The magnitude of magnetic flux density plot for one pole pairs

Figure 6 shows the magnitude of magnetic flux density plot for one pole pairs of AFPMSG by using FEA software. In this figure, the flux density in the magnet will be higher than the air gap flux density and flux density in the stator section.

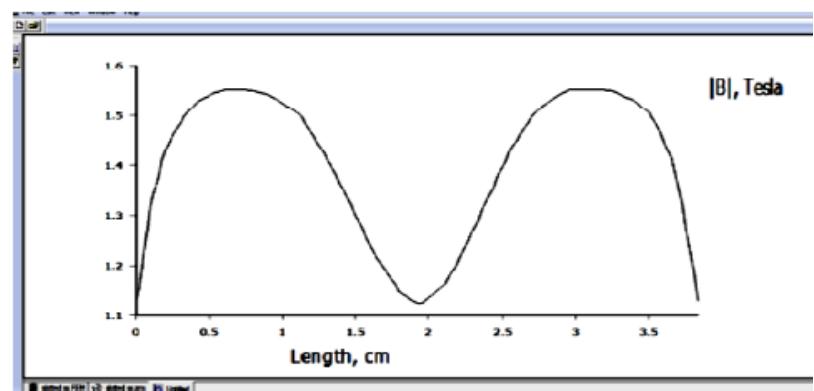

Figure 7. The magnitude of magnetic flux density plot for teeth and yoke

Figure 7 illustrates the magnetic flux density plot for stator teeth and stator yoke by using the finiteelement analysis. In this figure, the flux density in the teeth (which appears at $0.75 \mathrm{~cm}$ and the value is $1.55 \mathrm{~T}$ ) is slightly higher than the flux density in the stator yoke section (which appears at $0.4 \mathrm{~cm}$ and the value is $1.5 \mathrm{~T})$.

\subsection{Performance Analysis of Slotless Stator}

Moreover, the performance of $2 \mathrm{~kW}$ AFPMSG with slotless stator is analyzed with 2D finite-element analysis (method). 


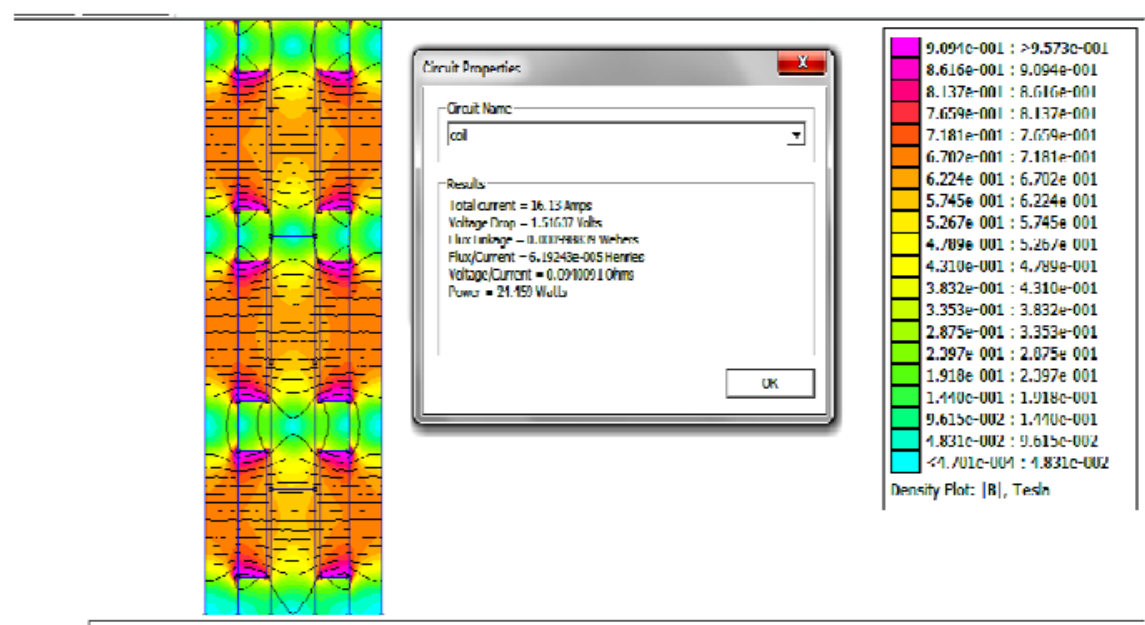

Figure 8. The magnetic flux density values for AFPMSG

Figure 8 shows the magnetic flux density values for AFPMSG by using finite-element analysis software. After running, these model with 2D FEA software display the magnetic flux density which can be plotted as a colour density plot.

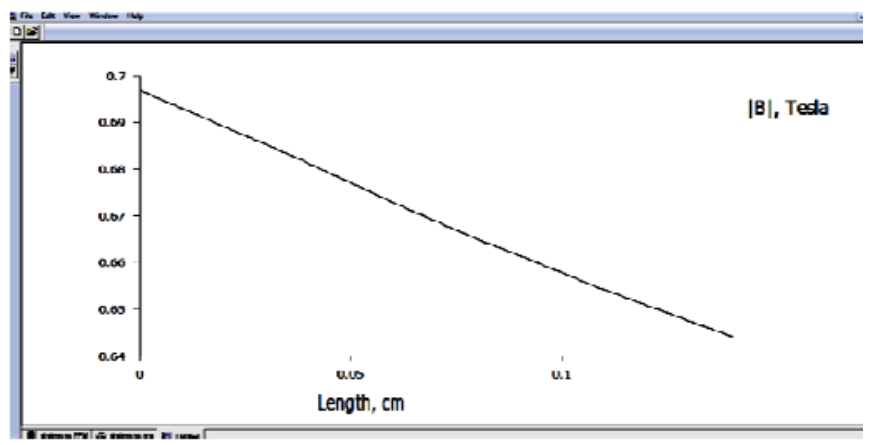

Figure 9. The peak value of air gap flux density plot for AFPMSG

Figure 9 is running results that are the air gap flux density plot for AFPMSG by using the finiteelement analysis. In this figure, the peak value of air gap flux density value is $0.698 \mathrm{~T}$.

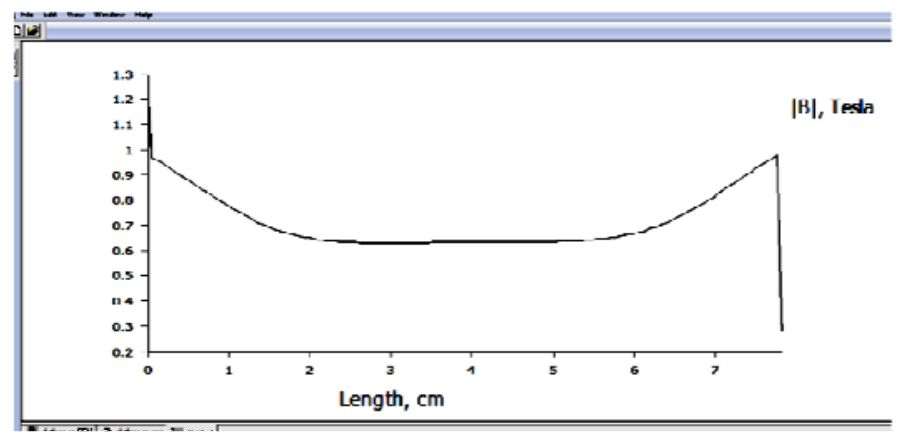

Figure 10. The magnitude of magnetic flux density plot for one pole pairs 
Figure 10 shows the magnitude of magnetic flux density plot for one pole pairs of AFPMSG by using FEA software. In this figure, the flux density in the magnet will be higher than the air gap flux density and flux density in the stator section.

\section{COMPARISON OF LOSSES AND EFFICIENCY BETWEEN SIZING EQUATION AND FEA SOFTWARE}

Table 5 shows the comparison of losses and efficiency between theoretical sizing equation values and finite element analysis results for slotted stator and slotless stator of double-sided AFPMSG. By applying the FEA method, the exact data of air-gap flux density is obtained and machine efficiency is recalculated by means of corrected data. Here, the efficiency of machine is higher than the theoretical sizing equation values. Finite element analysis leads to much more accurate magnetic fields solutions. Compare to the results i.e., the analytical result of copper losses, eddy current losses, iron losses and the machine efficiency which is based on the initial assumed flux density data to the result getting from the FEA software.

Table 5. Comparison of Losses and Efficiency between Sizing Equation and FEA Software

\begin{tabular}{cccccc}
\hline & & \multicolumn{2}{c}{ Sizing Equation } & \multicolumn{2}{c}{ 2D FEA } \\
Specifications & Units & (AFPMS) & \multicolumn{2}{c}{ (AFPSG) } \\
& & slotted & air cored & slotted & air cored \\
& & stator & stator & stator & stator \\
\hline Peak value of air gap flux density & $\mathrm{T}$ & 1.37 & 0.724 & 1.238 & 0.698 \\
Inductance & $\mathrm{mH}$ & 0.49 & 1.32 & 0.0074 & 0.06 \\
Resistance & $\Omega$ & 0.109 & 0.11 & 0.088 & 0.094 \\
Copper losses & $\mathrm{W}$ & 64.09 & 85.85 & 51.744 & 73.37 \\
Eddy current losses & $\mathrm{W}$ & - & 73.74 & - & 68.54 \\
Iron losses & $\mathrm{W}$ & 63.7 & - & 60.21 & - \\
Efficiency & $\%$ & 90 & 93 & 91.3 & 93.41 \\
\hline
\end{tabular}

\section{CONCLUSION}

This paper had described the design and performance of axial-flux double-sided permanent magnet synchronous generator with slotted stator and slotless stator. The copper losses, iron losses, eddy current losses and the machine efficiency between analytical sizing equation and FEA software are considered in the performance comparison of double-sided AFPMSG design. And then, the finite element method was used to compute the flux density in the generator components.

According to the FEA software the peak value of air gap flux density and the resistance are lower than the analytical sizing data for slotted stator and slotless stator. Because of the reducing flux density, the eddy current losses also reduced for air cored stator. Moreover, the air cored stator of AFPMSG machine copper loss is lower than that of the analytical sizing equation. According to the comparison results, the machine efficiency is slightly higher than that of the analytical sizing equation.

And then, the slotted stator teeth flux density value is lower than that of the initial sizing equation value. By reducing the teeth flux density, the iron losses is also reduced. When the slotted stator phase resistance is decreased than the theoretical equation value, it causes the copper losses in decrease. Because of the comparison results, the machine efficiency is higher than that of the analytical sizing equation. Therefore, it can be concluded that application of FEA can perform a great effort to get a more accurate machine designing process than using sizing equations only. Moreover, the performance of the slotless stator machine efficiency is greater than that of the slotted stator type.

\section{ACKNOWLEDGEMENTS}

First of all, the author would like to express deep gratitude to Dr. Yan Aung Oo, Professor, Head of Department of Electrical Power Engineering, Mandalay Technological University, for his close guidance, accomplished supervision, help, support and sharing ideas and experience during the research of thesis.

Finally, the author would like to express her deepest great thank to her father and mother for noble support to her all times and their unique loving kindness to attain her destination without any the trouble. 


\section{REFERENCES}

[1] Machines for Modulated Damping of Seismic Vibrations: Electrical and Thermal Modeling. IEEE Trans. Ind. Elect., 55(10): 3602-3610.

[2] B. J. Chalmers, W. Wu, and E. Spooner, "An axial-flux permanent-magnet generator for a gearless wind energy system,” IEEE Trans. Energy Convers.vol. 14, no. 2, pp. 251-257, Jun. 1999.

[3] E. Muljadi, C.P. Butterfield, and U.H. Wan, "Axial-flux modular permanent-magnet generator with a toroidal winding for wind-turbine applications," IEEE Trans. Ind. Appl., vol. 35, no. 4, pp. 831-836, Jul./Aug.1999.

[4] Ardresen EC, Keller R. Squrriel cage Induction Motor and Permanent Magnet Synchronous Motor. Symp on Power Electronic s, Electric Drives Conf. IEMDC'2001, Cambridge , MA, U.S.A., 2001, pp. 115-121.

[5] P. Acarnly, J. Mecrow, J.S. Burdess, J.N. Fawchett, J.G. Kelly and P.G. Dicinson, ”Design Principles for a Flywheel Energy Store for Road Vehicles", IEEE Trans. on Ind. Appl., vol. 32, no.6, pp. 1402-1407, Nov. 1996.

[6] Magnussen, et al., "Performance Evaluation of Permanent Magnet Synchronous Machines with Concentrated and Distributedd Windings Including the Effect of Field Weakening," in International Conference on Power Electronic, Machines and Drives (PEMD 2004), 2004, pp. 679-685.

[7] Gieras, J.F., Wing, M., 1997. Permanent Magnet Motor Technology - Design and Applications. New York: Marcel Dekker Inc, p. 444.

[8] Caricchi, F., Crescimbini, F., Di Napoli, A., Santini, E., 1992. Optimum CAD-CAE Design Axial-flux Permanent Magnet Motors. In Proceedings of International Conference on Electrical Machines, ICEM'92, pp. 637-641. 